\title{
Electronic Language Portfolio for Guided Independent Learning in Higher Education
}

\author{
Elena Kulikova \\ Lobachevsky State University of Nizhni Novgorod
}

\begin{abstract}
The paper presents an overview of the experience of effective organization of independent student learning using the electronic language portfolio at Lobachevsky State University of Nizhni Novgorod (Russia). An e-portfolio is a digital version of a paper-based portfolio. E-portfolios are an electronic representation of students' work - a purposeful digital collection that demonstrates their work, efforts, abilities, progress toward particular goals, self-reflection, and achievements. The electronic format allows a teacher to evaluate student portfolios via the Internet, a CD-ROM or thumb drive etc. Our student language e-portfolios are created by individual students with teacher input and help, taking into consideration non-linguistic orientation of the university and national characteristics of students. The paper considers the design of e-portfolio, views an e-portfolio as an additional assessment tool, and discusses the strengths and weaknesses of e-portfolio use. The implementation of the e-portfolio in the adult ESL classroom allows us to instill critical thinking skills into students, increase their motivation and the quality of education.
\end{abstract}

\section{Introduction}

Portfolio-based learning is being implemented more and more in a range of educational learning contexts worldwide in order to monitor students' professional development. The traditional educational portfolio has typically been paper-based and organized in some type of binder or folder. Such a portfolio is described as, "a purposeful collection of student work that exhibits the student's efforts, progress and achievements. The collection must include student participation in selecting contents, the criteria for selection, the criteria for judging merit, and evidence of student reflection" [1].

According to Anna Maria Lankes, an e-portfolio would contain the same information as the traditional paper-based portfolio, but a major difference would be that it could also include text, graphics, audio, video, and animation. The most significant difference is that instead of being stored as a hard copy, it would be stored electronically; either in a web-based format, or on a digital storage device such as a thumb drive or CD-ROM [2].

Web-based electronic portfolios (called 'webfolios') are favoured by many authors and especially by Barrett, however Galloway is not in favour of restricting electronic portfolios to online webpages because Galloway feels that well formatted and linked (where needed) Microsoft Office (Word, Excel, PowerPoint) documents would be just as effective as web pages while also maintaining the originality of the portfolio [3]. To generalize, most important benefit of any electronic portfolios is that they are more accessible than paperbased portfolios, and as a result, it is easier to update and edit them, share information and ideas with others.

Portfolios can be used in different areas for various purposes. There are usually two types of eportfolios: 'working' and 'showcase'. In a working portfolio, students are expected to contribute and edit the contents throughout the course; here the focus is more on process. In a 'showcase' portfolio, students only include their best work; here the focus is more on product [4]. In addition, there are individual and group portfolios [5].

Nowadays although portfolios are quite a wellknown approach to foreign language teaching, learning and assessment, their utilization in the language classroom is still relatively rare.

\section{E-Portfolio: Definition and Aims}

An e-portfolio is an electronic representation of a student's work - a purposeful digital collection that demonstrates student work, efforts, abilities, progress toward particular goals, self-reflection, and achievements. Our e-portfolio is a working (processoriented) portfolio with some features of a showcase portfolio. These student language e-portfolios are created by individual students with teacher input and help. The process of working on such a portfolio mainly involves three stages:

1) planning: setting goals and activating prior knowledge;

2) monitoring: reviewing one's progress towards the goals;

3) reflecting: modifying goals and/or adopting repair strategies [6]. 
The main aim is to enable students to apply the eportfolio as an extra language learning tool. Our portfolio is aimed at helping students to master the language, organize and remember linguistic material, facilitate students' reflection on their own learning, take more responsibility for their learning, and contribute to the formation of general cultural competence. E-portfolio users are viewed as active agents involved in constructing knowledge, refining their understanding, and learning socially through sharing with peers and teachers. The portfolio gives students the opportunity to reflect on their learning, stimulates students to seek answers to the following questions: what am I doing/learning? What for? What results do I have? How have I achieved them? Is it possible to make them better? What is my next step? In other words, the e-portfolio concept allows learners to represent their 'personal learning journeys' via electronic media.

To summarize, a language e-portfolio develops independent learning skills, language skills, and technical skills.

\section{E-Portfolio Design}

Our portfolio is designed for university students (Russians) doing a compulsory English course as part of non-language bachelor degrees. The national characteristics of Russian students were taken into consideration while creating the design of the eportfolio. They are good analytical skills, inquisitiveness, creativity; lack of motivation/laziness, hope for the best, carelessness, failure to take responsibility.

Our design significantly differs from the European Language Portfolio (ELP) which has a three-part format, consisting of a language passport, language biography and a dossier, although some of its elements are incorporated into our portfolio (for example, the descriptors of evaluating language skills according to A1-C2 levels) [7].

At the beginning of the course our students are introduced to the new tool of organizing their independent learning - e-portfolio. They are given all the necessary information and guidelines to start creating their individual portfolios, which are usually done in Microsoft Office Products (Word or Power Point) and sent to the teacher via e-mail. Since the eportfolio is a flexible tool, a lot of its aspects can be changed to meet students' needs while doing the course. All entries in a portfolio should be dated to track ongoing changes. The structure of our portfolio is shown beneath (Figure 1).
Student's Name and Group

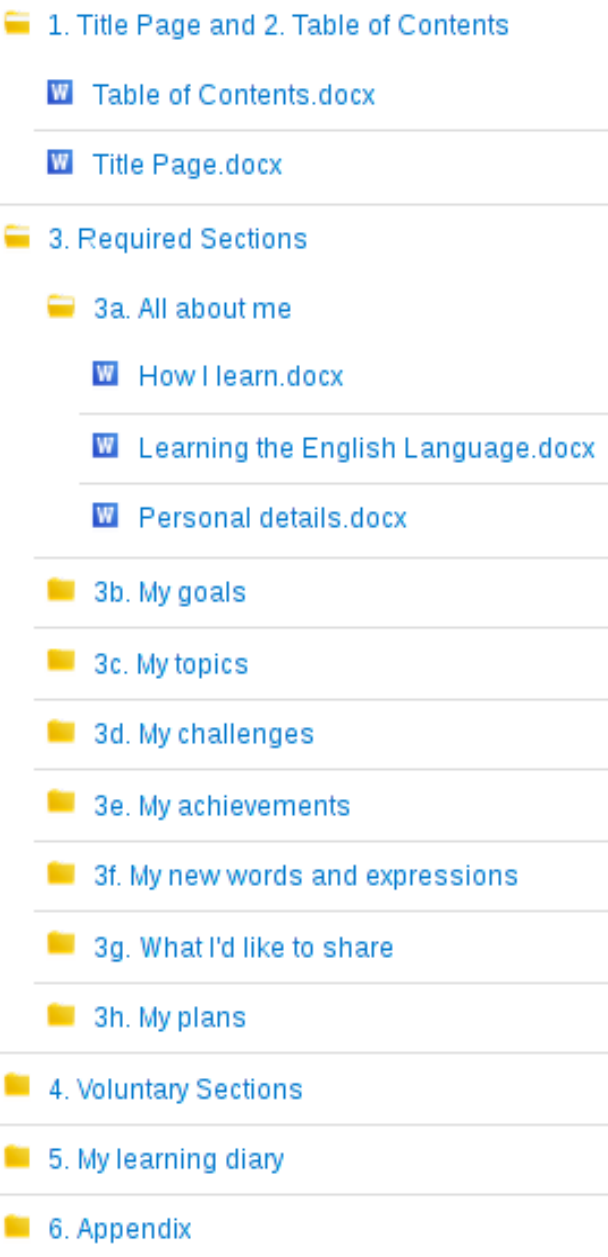

\section{Viewer comments box}

Figure 1. E-Portfolio Structure

1. Title Page (student's name, group number);

2. Table of Contents;

3. Required Sections:

3a. All about me. This section includes several subsections:

Personal details. Students are encouraged to fill in a short form, giving brief information about them. They can attach a photo, self-portrait, etc. Students can provide additional information (for example, some students describe their family members, hobbies and achievements).

How I learn. The student answers questions related to how they learn and grasp information (they are given some useful Internet links about different learning styles). This subsection helps students answer the questions: what can help me to learn? what prevents me from learning? 
$\checkmark \quad$ Learning the English language. Students answer questions about the importance of language learning, why they learn the language (to study, work, travel, etc.); they indicate most important skills (listening, speaking, reading or writing) to them. Students also evaluate themselves according to six reference levels defined within the Common European Framework of Reference for Languages.

3b. My goals. This section reflects the purpose of creating an e-portfolio (it is discussed together with the teacher), the goals for a semester, academic year. Students plan the ways of achieving them. Students are recommended to identify their goals according to the language level descriptors which they are given. By making short, accessible objectives, students can see what is strong and what needs more work. Students are also encouraged to choose the most effective language learning activities for themselves from the list given (they can add some activities to the list).

3c. My topics. This section presents the work of the students on the topics, and they do not just collect materials that are given in class. Each student develops their own learning style. They choose those learning strategies, techniques, graphic organizers, which provide optimum efficiency. This section may include: different charts, clusters, mind maps, word webs showing work on the topic / new words on the subject; students' monologues and dialogues; the results of group work in the classroom, lexical and grammatical tests, crosswords, additional material on the topics (articles, videos, illustrations, etc.).

3d. My challenges. In this section, students analyze their skills and difficulties in the studied material, ways to overcome them using the table given (Table 1).

Table 1. Analysis of Skills and Difficulties, Suggestion of Possible Solutions

\begin{tabular}{|c|c|c|}
\hline $\begin{array}{c}\text { I know/ } \\
\text { I can }\end{array}$ & $\begin{array}{c}\text { It's hard } \\
\text { for me ... }\end{array}$ & $\begin{array}{c}\text { I can deal with the } \\
\text { challenge if I ... }\end{array}$ \\
\hline & & \\
\hline
\end{tabular}

In addition, students demonstrate how they worked on the difficulties (for example, they do extra exercises or correct the mistakes in English papers).

3e. My achievements. This section includes best work samples, individual and group projects, certificates in the English language with the rationale explaining why each one is significant. For example, a sample of a group project (Figure 2) that some chemistry students considered the most successful with their reflective comment: "we carried out the group project "Crystals around us". I am proud of this work because we could do reseach in our professional sphere and present our project in English. Our teacher and classmates liked the project because it was interesting, our speaking was easy to understand, we also dealt with the follow-up questions well. Although we had some mistakes, everyone was able to understand us. We enjoyed to work in our team and grateful to our teacher for her help with organising our work. You can see some of the results of our project in the picture (sugar crystals with food colourings). We enjoyed our lollipops very much $\odot$ '.

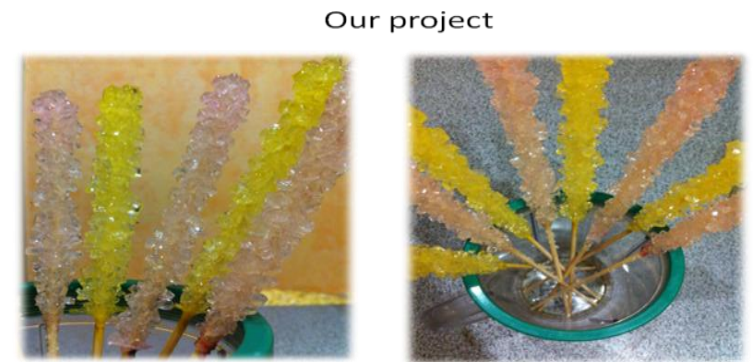

Figure 2. A Sample of a Group Project

Some students also provide information on the skills they have acquired throughout the semester in areas such as writing, reading, listening and speaking. Reflective notes are essential; they exhibit students' critical thinking capabilities, which may not be evident from a mere collection of their work.

3f. My new words and expressions. This section is devoted to the language material, which is not part of the main course. Students include words and expressions which they find interesting and/or useful. The teacher encourages students to use graphic organizers (charts, clusters), pictures, associations, definitions in English, transcription, synonyms, antonyms, collocations, and their own examples. Students work on these words and expressions and learn them by heart.

3g. What I'd like to share. This section may include useful links; informative and/or interesting information to share with classmates and the teacher.

3h. My plans. Students provide the list of future learning and social skills goals based on the current achievements, interests, and progress for the next semester. This section is one of the most important along with the section 'my achievements', as the portfolio is aimed primarily at the development of reflection skills. Unfortunately, students experience difficulty in completing this section, thus, it is necessary to monitor students regularly and counsel them individually.

4. Voluntary Sections. Since portfolio is a flexible learning tool, students and the teacher can introduce new sections if they feel the need to do it. These 
sections are not obligatory but they are welcome. For example, some students added sections 'my materials' (materials useful from their point of view which they found on the internet/books or wrote down in classes, but which they did not create themselves), 'my texts' (different texts interesting from the viewpoint of students and work with these texts), and 'my impressions' (students' impressions of the course materials, classes, communication).

5. My learning diary. Every week, students send the teacher a report (my learning diary) via e-mail on their independent work on the portfolio. The report is modeled on that one given by the teacher (Table 2)

Table 2. Learning Diary

\begin{tabular}{|l|l|}
\hline \multicolumn{2}{|c|}{ My learning diary } \\
\hline Name: & \\
\hline Group: & \\
\hline Date (from...to): & \\
\hline \multicolumn{2}{|c|}{ In the past week I have learnt: } \\
\hline Topics & \\
\hline New vocabulary & \\
\hline New grammar & \\
\hline Listening & \\
\hline Reading & \\
\hline Speaking & \\
\hline Writing & \\
\hline I now know about: & \\
\hline I need to work more on: & \\
\hline Have I achieved my previous goal? & \\
\hline What is my next learning goal? & \\
\hline How do I intend to achieve my goal? & \\
\hline $\begin{array}{l}\text { How much time can I devote each } \\
\text { day/week to achieving my goal? }\end{array}$ & \\
\hline
\end{tabular}

Preparing such a report helps students analyze and plan their work, set realistic objectives, take responsibility for achieving results. As for the teacher the report serves as an additional means of controlling students' learning activities and helps to guide students.

6. Appendix. It includes a list of references, wellorganized materials that are given in class, completed home assignments given by the teacher.

7. Viewer comments box. It is devoted to the teacher's and students' comments (reviews). At the end of the semester students are united in small groups (3-4 people) to review the portfolio of each member of the group. Observing the different work shown in the group, students learn from their peers and their work. Students emphasize advantages and disadvantages, if any, draw portfolio owner's attention to things that must be further developed, improved. They single out ideas, portfolio elements which they like most of all. If the group members do not understand anything, then they leave the questions in this part of the portfolio. In accordance with the evaluation criteria students choose the best portfolio of the group and present it in class. This appropriate feedback from the teachers and students seems to be very effective to promote student's learning motivation. Students improve their portfolios, taking into account criticism of the student group; answer the questions, if any, by the exam.

\section{E-Portfolio as an Additional Assessment Tool}

E-portfolios give a big picture of the dynamics of educational and creative activity of students, orientation of their interests, the nature and depth of their knowledge, and help evaluate university students' learning outcomes.

Two of the most widely used assessments in education today are summative and formative. Formative assessment measures student progress, its primary focus is to identify areas that may need improvement. This assessment typically is not graded. Summative assessment is the process of evaluating (and grading) the learning of students at a point in time. Grades are usually an outcome of summative assessment. Summative assessment is more product-oriented and evaluates the final product/result, whereas formative assessment is progress-oriented and focuses on the process of achieving a particular result.

In our course we use both formative and summative assessments. Our portfolio is an example of formative assessment; it provides a rich view of learning process, it examines students' progress toward goals by collecting a variety of evidence of independent learning activities over an extended period of time, instead of a specific separate point of time. It helps to show what the student is capable of, his or her potential.

By building a portfolio, students are able to set goals, reflect on their learning process and results, track their progress, and make self-assessment and peer-assessment by consulting the criteria with the teacher's guidance.

Since it is thought that the teacher and students should collaborate in the process of assessment, the teacher and students agreed on the following criteria for assessing portfolios:

- careful completion of all required sections;

- ample evidence of independent learning work on the material studied in class and outside of it;

- $\quad$ individual design and creativity; 
- formation of learning skills such as the ability to set goals, plan and adjust activities in accordance with the goals; the ability to use information resources; the ability to structure information; analysis and synthesis skills etc.;

- student's reflection on his/her learning and development;

usefulness to the student.

Students' work on portfolios is rated at the end of each semester by other students and the teacher as of poor (insufficient)/good (sufficient)/high quality. Students take the ratings and comments into consideration and improve their portfolios by the exam.

Since one of the challenges with regard to using portfolio assessment concerns its reliability, it is reasonable to combine the portfolio assessment with the traditional forms of assessment such as usual exams, final tests. The portfolio assessment contributes to final assessment (evaluation), grade.

\section{Strengths and Challenges}

The use of the e-portfolio has a number of positive implications for students and the teacher.

The use of an e-portfolio enables students to: become more active and disciplined learners, gain a sense of responsibility for their work, plan their learning, work on portfolios on their own time; gain more profound knowledge of the language; develop their own meta-cognitive skills, be more aware of how they are learning, be more aware of their own strengths and weaknesses; monitor, review, and assess their own progress; update the content of eportfolio from time to time according to the requirements and their interests; improve computer literacy; identify opportunities for learning and personal development outside the curriculum.

The use of an e-portfolio enables teachers to: develop more independent/ autonomous learners; create an environment that makes student feel good about participating; alleviate problems connected with the diverse leaning skills, styles, and previous knowledge; intensify students' language learning; instill critical thinking skills into students; draw attention to the wider skills that the academic discipline gives to students; implement alternative assessment; get feedback on teaching and improve it necessary.

Despite the advantages the use of the portfolio offers, it is not free from challenges. The use of an eportfolio may be strange for students, since they are strongly influenced by traditional contact-teaching and summative assessment. It is also difficult to make students think about their actions critically and evaluate and develop them instead of just describing them. Therefore, the use of the portfolio requires good instructions, sufficient guidance and support during studying. Finally, one of the main challenges regarding portfolio implementation and management is an increase in the teacher and students' workloads. Portfolio building takes students time, effort and hard work. During the process of developing portfolios by students, the teacher is involved in communicating with individual students or small groups, reviewing portfolio contents, commenting on students' work. It is extremely time-consuming for the teacher to make portfolio assessment in addition to traditional grading.

\section{Conclusion}

An e-portfolio is a powerful tool which can enhance the foreign language teaching and learning, and improve learning outcomes. E-portfolios provide students with a system for not just language learning, but also independent learning, which is the requirement of modern education. Independent studying implies active learners who are aimed at taking responsibility for their work and success. At the same time teacher guidance is an important prerequisite for effective independent learning. An eportfolio is a tool which creates conditions for organizing independent student work during the course, and promotes the critical-reflexive thinking style.

It should be noted that despite the majority of the students consider that the e-portfolio is a helpful learning tool, some students are not so confident about producing their portfolio. This tool requires the teacher's commitment to work, thinking 'outside the box', and aspirations towards knowledge of how to design and manage portfolios more efficiently. All of these facts lead to the conclusion that implementation of e-portfolios needs to be carefully planned, designed and tested to become a truly effective teaching and assessment tool so that it could enrich and not hinder learning process.

\section{References}

[1] Paulson, F.L., Paulson, P.R., \& Meyer, C. A. (1991) What makes a portfolio a portfolio? Educational Leadership, 48 (5), pp. 60-63.

[2] Lankes, A. M. (1995). Electronic portfolios: A new idea in assessment. ERIC Clearinghouse on Information and Technology. Syracuse, New York: Syracuse University. http://www.ericdigests.org/1996-3/idea.htm (27 December 2014).

[3] Ali, S. Y. (2005) An Introduction to Electronic Portfolios in the Language Classroom. 
The Internet TESL Journal, Vol. XI, No. 8. http://iteslj.org/Techniques/Ali-Portfolios.html (28 December 2014).

[4] Grant, V. (2010) To 'e' or not to 'e': Electronic portfolios in the adult ESL classroom. Hawaii Pacific University TESOL Working Paper Series $8(1,2)$, pp. 2024.

[5] Johnson D.W., Johnson R.T. (1999) Learning Together and Alone: Cooperative, Competitive, and Individualistic Learning. Allyn and Bacon, $260 \mathrm{p}$.

[6] Chau, J. and Cheng, G. (2010) Towards understanding the potential of e-portfolios for independent learning: A qualitative study. Australasian Journal of Educational Technology, 26(7), pp. 932-950.

[7] http://www.coe.int/t/dg4/education/elp/(29 December 2014). 